\title{
Administration of recombinant human GHRH-1,44-amide for 3 months reduces abdominal visceral fat mass and increases physical performance measures in postmenopausal women
}

\author{
Johannes D Veldhuis, James M Patrie ${ }^{1}$, Kirsten Frick ${ }^{4}$, Judith Y Weltman ${ }^{2,4}$ and Arthur L Weltman ${ }^{2,3,4}$ \\ Division of Endocrinology and Metabolism, Department of Internal Medicine, General Clinical Research Center, Mayo School of Graduate Medical \\ Education, Mayo Clinic, 200 First Street SW, Rochester, MN 55905, USA and Departments of ${ }^{1}$ Health Evaluation Services, ${ }^{2}$ Human Services and \\ ${ }^{3}$ Internal Medicine, and ${ }^{4}$ General Clinical Research Center, University of Virginia Health System, Charlottesville, VA 22908 , USA
}

(Correspondence should be addressed to J D Veldhuis; Email: veldhuis.johannes@mayo.edu)

\begin{abstract}
Objective: A recent study indicated that twice-daily s.c. administration of a high dose of recombinant human GHRH-1,44-amide (GHRH) for 90 days can alter body composition in healthy older men. No data establish whether this is also true in postmenopausal women. The present study tests the hypothesis that the same GHRH regimen applied in women will: (i) elevate both IGF-I and GH concentrations; and (ii) reduce abdominal visceral fat mass, augment total body water and enhance functional performance.

Design: Ten postmenopausal volunteers underwent baseline study and then received $1 \mathrm{mg}$ GHRH twice daily s.c. for 3 months.

Methods: Statistical comparisons were made with preintervention baseline data.

Results: GHRH administration stimulated: (i) a mean 98 $14 \%$ elevation of overnight GH concentrations after administration of the peptide for 1 and 3 months $(P<0.005)$; (ii) a sustained $71 \pm 3.5 \%$ rise in IGF-I concentrations over the interval from 2 weeks to 3 months $(P<0.0012)$; (iii) a $16 \pm 7 \%$ reduction in abdominal visceral fat mass $(P=0.029)$ and a $14 \pm 5 \%$ increase in tritiated water space $(P<0.025)$; (iv) an abbreviation of the times required to walk $30 \mathrm{~m}$ $(P=0.015)$ and ascend two flights of stairs $(P=0.003)$. Most $(70 \%)$ subjects experienced local skin reactivity. There were no systemic adverse events.

Conclusions: A 3-month regimen of GHRH supplementation in postmenopausal women can stimulate GH and IGF-I production, reduce abdominal visceral fat and improve selected measures of physical performance, while inducing significant local skin reactivity.
\end{abstract}

European Journal of Endocrinology 153 669-677

\section{Introduction}

Healthy aging results in a progressive reduction in growth hormone $(\mathrm{GH})$ secretion rates and insulin-like growth factor-I (IGF-I) concentrations (1). Associated physical features include sarcopenia, osteopenia, increased visceral fat mass, heightened atherosclerotic risk, impaired insulin action and reduced strength, well being and endurance (2). Many of these signs and symptoms are also characteristic of GH deficiency (3-5). Although IGF-I concentrations decline in aging, the hepatic actions of $\mathrm{GH}$ are preserved in older adults, since low doses of recombinant human (rh) GH stimulate comparable increments in total IGF-I concentrations in elderly and young volunteers $(6,7)$.

The age-related fall in $\mathrm{GH}$ secretion may reflect heightened hypothalamic somatostatinergic inhibition and/or diminished hypothalamo-pituitary drive by the potent secretagogues, GH-releasing hormone (GHRH) and/or GH-releasing peptide (GHRP, ghrelin) $(1,8,9)$. Secretagogue deficiency is suggested but not proven by some interventional studies. For example, single or repeated daily injection or continuous s.c. infusion of GHRH or GHRP-2 elevates GH and IGF-I concentrations for intervals of $24 \mathrm{~h}$ to 4 months in elderly men (10-15). However, only one of these interventions altered body composition significantly (15). In contrast, GH supplementation consistently decreases intraabdominal fat and increases lean body mass in GHdeficient adults $(16,17)$. Whether an inadequate dose and/or frequency of secretagogue administration accounts for the lack of whole-body effects in earlier regimens is not known. The issue is important, because a high dose $(1 \mathrm{mg})$ of rhGHRH administered twice daily for 3 months doubled mean concentrations of GH and 
IGF-I, reduced total abdominal fat content, increased lean body mass and improved certain measures of physical performance in older men (15). There are no comparable data in women.

Two studies of secretagogue supplementation have included postmenopausal women. One used GHRP but did not assess body composition (14), and the other found that nightly injection of GHRH-1,29 for 4 months did not alter body composition (13). In view of the recent experience in older men given a high dose of GHRH twice daily for 3 months (15), the present investigation tests the hypotheses that the same regimen will achieve comparable biochemical, body compositional and performance-related improvements in postmenopausal women.

\section{Methods}

\section{Subjects}

Ten healthy ambulatory, community-dwelling, recreationally active women participated. Volunteers comprised postmenopausal women capable of administering GHRH twice daily by s.c. injection, performing intensive functional tests, and undergoing repetitive blood sampling at baseline and after 1 and 3 months of intervention. Subjects provided prior written voluntary informed consent approved by the Institutional Review Board. Physical characteristics were (mean with range in parentheses): age, $57(51-73)$ years; height, $166(161-172) \mathrm{cm}$; weight, $73(69-78) \mathrm{kg}$. Each participant had an unremarkable medical history, physical examination and screening biochemical tests of hepatic, renal, metabolic, hematologic and endocrine function. Four women continued use of conventional postmenopausal hormone replacement therapy (HRT). Screening data revealed concentrations of follicle-stimulating hormone (FSH) >30 IU/l (normal youngadult range, $2-8 \mathrm{IU} / \mathrm{l}$ ); total testosterone (range) $10-$ $58 \mathrm{ng} / \mathrm{dl}$ (multiply by 0.0347 for $\mathrm{nmol} / \mathrm{l}$ ); and estradiol $10-56 \mathrm{pg} / \mathrm{ml}$ (multiply by 3.67 for $\mathrm{pmol} / \mathrm{l}$ ). Exclusionary criteria were: recent weight loss or gain exceeding $3 \mathrm{~kg}$ in 6 weeks; an abnormal mammogram within the preceding year; acute or chronic systemic disease; psychiatric illness; orthopedic handicaps that would limit exercise and balance testing; drug or alcohol abuse; concurrent use of psycho- or neuroactive medications; exposure to anabolic steroids or systemic glucocorticoids; anemia (hemoglobin $<14 \mathrm{~g} / \mathrm{l}$ ); cerebro-, cardio- or peripheral arteriovascular disease; reluctance to inject peptide twice daily for 3 months as an outpatient; lack of prompt access to the General Clinical Research Center (GCRC); and incompetence or unwillingness to provide written informed consent.

\section{Clinical protocol}

Volunteers were admitted to the GCRC on three occasions to undergo blood sampling for 12 hours overnight and metabolic studies the next day; viz. at baseline and after 1 and 3 months of twice-daily s.c. injection of $1 \mathrm{mg}$ GHRH (rhGHRH-1,44-amide, BioNebraska, Inc., Lincoln, NE, USA). The peptide was administered at $2200 \mathrm{~h}$ and $0800 \mathrm{~h}$ in pre-filled syringes labeled with the volunteer's name, protocol number and date. Peptide was reconstituted by dilution in $1 \mathrm{ml}$ sterile water, and dispensed weekly by the Investigational Drug Pharmacy. Syringes were kept refrigerated. Volunteers continued their usual daily activities, dietary habits and recreational level of exercise. Four women continued HRT. The project was approved by the US Food and Drug Administration (Washington, DC, USA) under an investigator-initiated new drug file.

In a pilot study, three out of the first four volunteers given $4 \mathrm{mg}$ GHRH twice daily were removed from participation due to significant local edema at the site of injection $(>3 \mathrm{~cm})$ and/or (two women) urticaria at sites remote from the injection. Hence, the $4 \mathrm{mg}$ dose was disapproved due to adverse effects.

\section{In-patient studies}

To obviate confounding of GH and IGF-I measurements by variable nutrient intake, enrollees were admitted to the GCRC in the morning after ingesting a standardized breakfast at home (nutrient composition: $55 \%$ carbohydrate, $15 \%$ protein and $30 \%$ fat). Thereafter, participants received standardized meals (above) of $12.5 \mathrm{kcal} / \mathrm{kg}$ at $1200 \mathrm{~h}$ and $1700 \mathrm{~h}$ in the GCRC, and remained fasting overnight. At $1800 \mathrm{~h}$, an indwelling i.v. catheter was placed in an antecubital vein to allow repetitive blood sampling $(1.5 \mathrm{ml})$ every $10 \mathrm{~min}$ for 12 hours beginning at $2000 \mathrm{~h}$. Vigorous exercise, hypnotics, caffeinated beverages, smoking and alcohol use were disallowed. Room lights were extinguished at $2300 \mathrm{~h}$.

\section{Functional assessments}

Strength Isokinetic eccentric and concentric strength of the quadriceps femoris and biceps femoris muscle groups was assessed using the Kin-Com II isokinetic dynamometer (Chattex, Corp., Hixson, TN, USA). After familiarization with the procedure, subjects performed three knee flexions and extensions at a calibrated velocity of 60 degrees per second. To estimate quadriceps strength: the lateral epicondyle of the knee was aligned with the axis of the dynamometer; the inferior edge of the force pad was placed directly superior to the medial malleolus; and Velcro straps were applied across the hips, thigh and ankle for stabilization. Gravity correction was performed with the knee at $0^{\circ}$ flexion.

Balance Quantitative measures were: (i) the duration of standing (in seconds) on one leg with eyes open and closed; (ii) dual-limb and single-limb stance protocols 
with eyes open and closed under static and dynamic conditions on the Chattex Balance System (Chattanooga Group Inc., Hixson, TN, USA); (iii) dynamic platform tilting to force plantar flexion and dorsiflexion; (iv) the sharpened Rhomberg (timed standing heel-to-toe with dominant foot in front and eyes closed) (18).

Physical performance Functional motor capability was assessed by a timed stair climb and $30 \mathrm{~m}$ walk. Subjects were asked to descend two flights of stairs, wait $1 \mathrm{~min}$ and ascend as quickly as possible using the railing for balance only. The timed $30 \mathrm{~m}$ walk was conducted twice on a level unobstructed passageway with $1 \mathrm{~min}$ of rest between to obtain a mean value.

Flexibility Hamstring extension/lower-back flexibility was assessed using a sit-and-reach apparatus. Volunteers sat with feet against the surface, and reached as far forward as possible with knees extended. Positive scores (mean of three trials) indicate the number of inches of extension beyond the toes (and, conversely, for negative scores).

\section{Body composition analysis}

Total body water Participants received tritiated water $(<0.12 \mathrm{mSv})$ orally at $0900 \mathrm{~h}$ on the second morning of study. Blood and urine samples were collected 1, 2, 3 and 4 hours later. Equilibrated radioactivity was quantitated by liquid scintillography. The density of water at body temperature was taken as $0.9937 \mathrm{~kg} / \mathrm{l}$ (19).

Percentage body fat For hydrostatic densitometric estimates, subjects were weighed in air on an Accu-weigh beam scale accurate to $0.1 \mathrm{~kg}$, and weighed again underwater on a Chatillon autopsy scale accurate to $10 \mathrm{~g}$ (20). Residual lung volume was measured by $\mathrm{O}_{2}$ dilution (21). Calculated percentages of total body fat were made as described previously (19).

Bone mineral content Dual-energy X-ray absorptiometry (DEXA) was used to estimate total bone mineral ash and skeletal density at the left trochanter (Hologic QDR-2000, pencil beam mode, enhanced whole-body analysis software version 5.64, Waltham, MA, USA). Absorbance was multiplied by 1.279. A single trained investigator analyzed all DEXA records (19).

Abdominal visceral fat (AVF) AVF was determined by single-slice computed axial tomography (CT) at $140 \mathrm{kV}$ energy and a slice thickness $0.5 \mathrm{~cm}$ at the L4-L5 intervertebral space with no angulation (22) (Picker PQ 5000 and by Voxel Q 3D image processing (Picker International, Cleveland, OH, USA)). Subcutaneous fat and AVF (and thereby total abdominal fat) were calculated by delineating anatomical landmarks with a mouse-computer interface, and computing the cross-sectional area within the absorbance-attenuation range -190 to -30 Hounsfield units (23).

Peak oxygen consumption ( $\left.\mathbf{V}_{\mathrm{O}_{2}, \max }\right)$ Volunteers performed graded bicycle ergometry as outpatients to determine the individual lactate threshold (LT) and $V_{\mathrm{O}_{2} \text {,max }}$ at baseline and $24-48$ hours prior to the 1- and 3-month studies in the GCRC. Initial power output was $20 \mathrm{~W}$, this demand was increased by $15 \mathrm{~W}$ every $3 \mathrm{~min}$ until volitional exhaustion. Forearm venous lactate concentrations were monitored at rest and during the last $15 \mathrm{~s}$ of each power stage (Yellow Springs Instruments, 2700 Select Biochemistry Analyzer, Yellow Springs, OH, USA). The LT was taken as the highest power output achieved before onset of the curvilinear increase in lactate concentrations (exceeding at least $0.2 \mathrm{mM}$ ). Oxygen consumption was quantitated by open-circuit spirometry (Sensormedics Metabolic Cart 229, Yorba Linda, CA, USA) and heart rate by electrocardiography (Marquette Max-1). $V_{\mathrm{O}_{2} \text {, max }}$ was defined as $V_{\mathrm{O}_{2}}$ uptake at voluntary exhaustion.

\section{Hormone assays}

Mean GH concentrations were determined by automated immuno-chemiluminescence assay of sera collected every $10 \mathrm{~min}$ from $2000 \mathrm{~h}$ to $0800 \mathrm{~h}$ overnight (Nichols Institute Diagnostics, San Clemente, CA, USA) $(24,25)$. Assay sensitivity (at 3 S.D. above the zero-dose tube) was $0.005 \mu \mathrm{g} / \mathrm{l}$. Median intra-assay and interassay coefficients of variation were 5.2 and $8.3 \%$ respectively. No values fell below $0.030 \mu \mathrm{g} / \mathrm{l}$ in the present study. Fasting $(0800 \mathrm{~h})$ concentrations of total IGF-I (Nichols Institute Diagnostics) and testosterone and estradiol (Diagnostic Products Inc., Webster, TX) were determined as reported previously (26).

\section{Deconvolution analysis}

Biexponential deconvolution analysis was used to quantitate basal and pulsatile $\mathrm{GH}$ secretion from each 12-h concentration profile (27). In view of parameter interdependence, estimation was conditioned statistically on mean populational GH kinetics and a priori pulse times (28); viz. GH half-lives were 3.5 and 20.8 min (fractional slow decay 0.63) (29), and putative pulse times were determined by Cluster (discrete peak-detection) analysis at a nominal $P<0.05$ falsepositive rate $(2 \times 1$ cluster size with $t=2.0 / 2.0)$ (30). GH elimination kinetics and peak positions were held constant, allowing simultaneous estimation of the mass (or integral) of Gaussian secretory events and basal secretion (initially estimated as corresponding to the lowest $5 \%$ concentration). The outcomes were basal (time-invariant), pulsatile (sum of secretory-burst mass) and total (sum of basal and pulsatile) $\mathrm{GH}$ secretion expressed in $\mu \mathrm{g} / \mathrm{l}$ per 12 hours. The foregoing modifications are required for 
reliable conditional parameter estimation, as established more recently by statistical verification and experimental validation $(31,32)$.

\section{Approximate entropy (ApEn)}

ApEn provides a scale- and model-independent regularity statistic to quantitate the orderliness of serial measurements (33). Higher ApEn values denoted greater relative randomness or disorderliness of subpatterns. Mathematical models and clinical experiments establish that reduced pattern orderliness is a barometer of increased feedforward and/or decreased feedback within a neuroendocrine axis with high sensitivity and specificity (both $>90 \%)(34,35)$.

\section{Statistical methods}

Outcomes are reported as the arithmetic mean \pm S.E.M. For discussion purposes, relative responses (fold-effects) are given as the geometric mean ratio (and 95\% statistical confidence intervals (CIs)) of the value observed at 1 month or 3 months to that estimated at baseline in the same individual. To adjust for within-subject correlations, the statistical model comprised hierarchical mixed-effect one-way ANCOVA, wherein the baseline outcome served as the covariate (36). The model-specification parameter was the duration of intervention (1 and 3 months) (37). Logarithmic transformation was utilized to limit heterogeneity of variance. The equal-slopes assumption of the ANCOVA structure was verified by a generalized $F$-ratio test, followed by restricted maximum-likelihood estimation of parameters. Rejection of pre-specified hypotheses was based on a multiple-comparison experiment-wise Type I error rate of $<0.05$ using Fisher's least-significant difference (LSD) test (36). Computations were performed using PROC MIXED in SAS version 8.0 (SAS Institute Inc., Cary, NC, USA).

\section{Results}

GHRH administration twice daily increased mean overnight $\mathrm{GH}$ concentrations $(\mu \mathrm{g} / \mathrm{l})$ from a baseline value of $0.71 \pm 0.18$ to $1.4 \pm 0.26$ ( 1 month) and $1.4 \pm 0.20$ (3 months) (both $P<0.005$ vs baseline; $P=$ NS for 1 vs 3 months comparison; Fig. 1a). The incremental increase over baseline at both time points averaged $98 \pm 14 \%$. Fasting serum IGF-I concentrations, measured at baseline and after 2, 4, 8 and 12 weeks of intervention, rose from a baseline mean of $109 \pm 14 \mu \mathrm{g} / \mathrm{l} \quad$ to $204 \pm 35 \mu \mathrm{g} / \mathrm{l}, \quad(P=0.006), \quad$ and remained comparably elevated at all time points thereafter $(0.012>P>0.001$ vs baseline; Fig. $1 b)$. The average percentage increase above baseline was $71 \pm 3.5 \%$. Exploratory subgroup analysis showed that IGF-I increments in women receiving HRT $(n=4)$ did
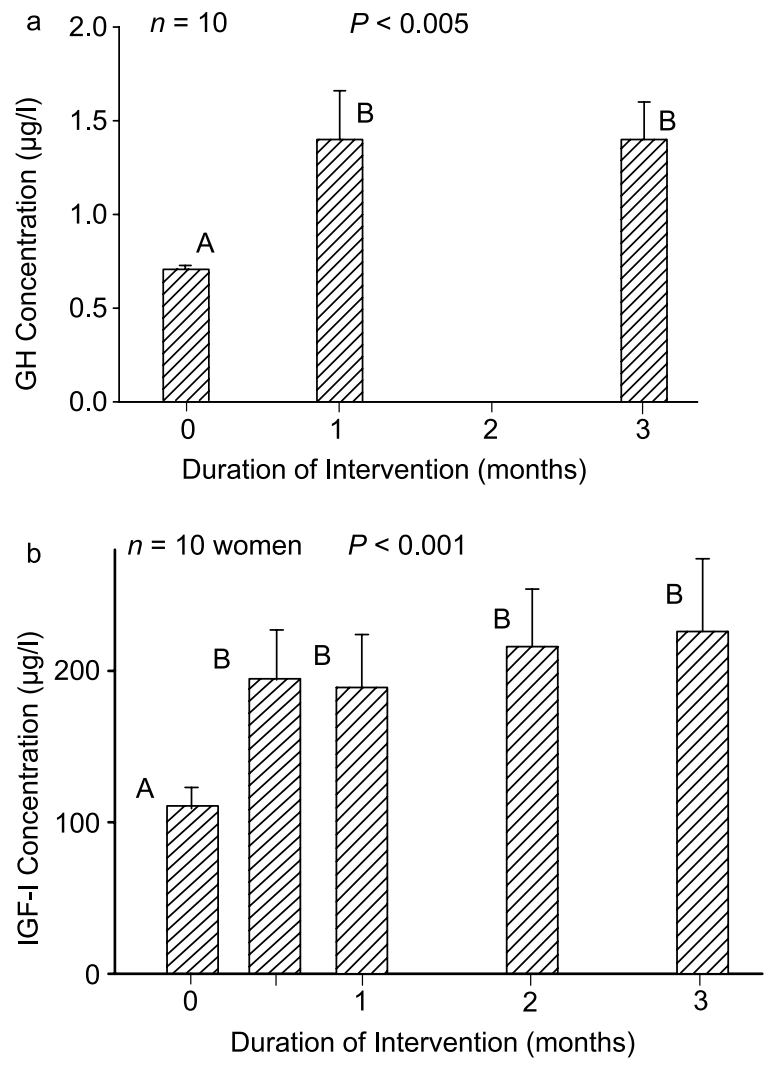

Figure 1 Impact of administering rhGHRH (1 mg s.c. twice daily) for 3 months on overnight $(12 \mathrm{~h})$ mean GH concentrations determined at baseline (time zero) and after 1 and 3 months (a) and on fasting IGF-I concentrations measured at baseline (time zero) and after 0.5, 1, 2 and 3 months (b). Data are the means \pm S.E.M. ( $n=10$ postmenopausal volunteers). Means with different letters differ significantly. The overall interventional $P$ value is indicated.

not differ from those in individuals not receiving HRT $(n=6)$.

The principal effects of GHRH were to decrease intraabdominal visceral fat area by $16 \%(2-28 \%, 95 \% \mathrm{CI})$; $P=0.029)$ and increase total body water by $14 \%$ $(4-23 \% ; P<0.025$; Fig. 2). Lean body mass did not increase significantly.

Body compositional data that did not change are reported in Table 1 (hydrodensitometry), Table 2 (CT estimates of total abdominal fat and thigh muscle area) and Table 3 (DEXA measurements of total body fat, water and bone mineral content).

Figure 3 depicts $30 \mathrm{~m}$ walking times, which decreased by $14 \%$ (range, $9-19 \% ; P=0.015$; Fig. $3 b$ ) and stair-climb times, which fell by $9 \%$ (range, $4-13 \%$; $P=0.003$; Fig. $3 b$ ) at 3 months compared with baseline.

Stable performance outcomes $(P>0.05$ for 3 months vs baseline) are summarized in Table 4 (exercise function), Table 5 (strength at knees) and Table 6 (balance measures and sit-and-reach distance). 


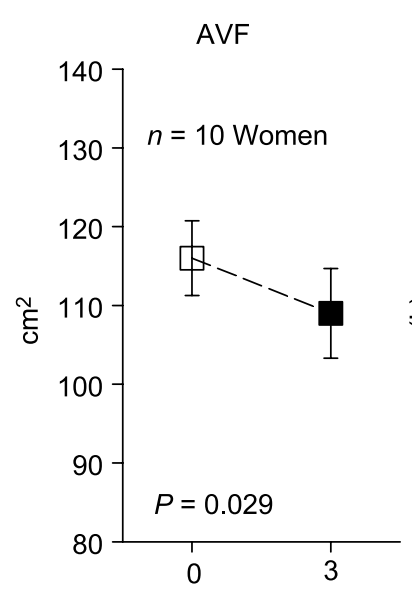

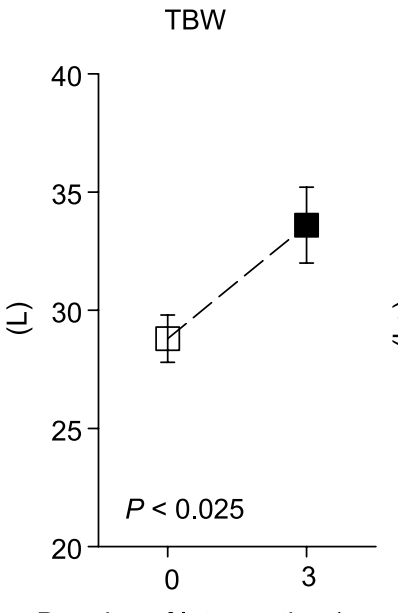

Duration of Intervention (months)
LBM

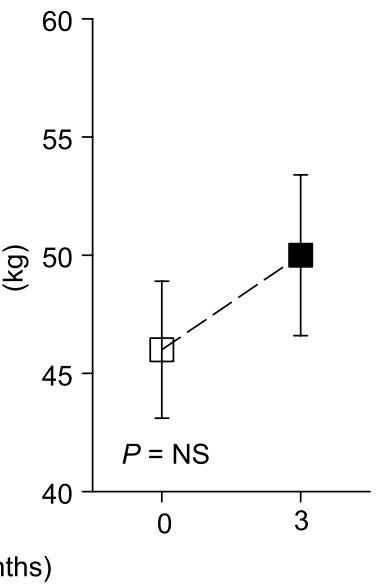

Figure 2 Intra-abdominal visceral fat mass (AVF), total body water (TBW) and lean body mass (LBM) in ten postmenopausal women assessed at baseline and after 3 months of rhGHRH administration. Data are presented as described in the legend of Fig. 1, except that statistical values apply to the indicated paired outcomes.
Pulsatile and basal GH secretion rates were estimated from the 12-h overnight (10-min) GH concentration profiles using deconvolution analysis. As in the case of mean $\mathrm{GH}$ concentrations, pulsatile $\mathrm{GH}$ release rose

Table 1 Hydrodensitometry estimates.

\begin{tabular}{lcc}
\hline Measure & Baseline & 3 months \\
\hline Body density $\left(\mathrm{g} / \mathrm{cm}^{3}\right)$ & $1.006 \pm 0.007$ & $1.011 \pm 0.008$ \\
Fat $(\%)$ & $40 \pm 2.2$ & $38 \pm 3.9$ \\
FM $(\mathrm{kg})$ & $32 \pm 4.5$ & $30 \pm 5.0$ \\
FFM $(\mathrm{kg})$ & $46 \pm 2.9$ & $50 \pm 3.6$ \\
Body weight $(\mathrm{kg})$ & $78 \pm 7.2$ & $78 \pm 7.1$ \\
\hline
\end{tabular}

Data are the means \pm S.E.M. $(n=10)$. Values at baseline and at 3 months do not differ significantly. FM, fat mass; FFM, free-fat mass.

Table 2 CT estimates of body composition $\left(\mathrm{cm}^{2}\right)$.

\begin{tabular}{lcc}
\hline Measure & Baseline & 3 months \\
\hline $\begin{array}{l}\text { Total abdominal fat } \\
\text { Thigh fat area }\end{array}$ & $543 \pm 72$ & $503 \pm 87$ \\
$\quad$ Right & $105 \pm 18$ & $110 \pm 11$ \\
$\quad$ Left & $105 \pm 20$ & $110 \pm 25$ \\
$\begin{array}{l}\text { Thigh muscle area } \\
\quad \text { Right }\end{array}$ & $95 \pm 13$ & $109 \pm 12$ \\
$\quad$ Left & $94 \pm 12$ & $107 \pm 87$ \\
\hline
\end{tabular}

Comparisons at 3-months do not differ. Values are means \pm S.E.M. $(n=10)$. Visceral fat area is shown in Fig. 2.

Table 3 DEXA estimates of body composition.

\begin{tabular}{lcc}
\hline Measure & Baseline & 3 months \\
\hline $\mathrm{BMC}\left(\mathrm{g} \times 10^{3}\right)$ & $2.4 \pm 0.14$ & $2.4 \pm 0.13$ \\
$\mathrm{BMD}\left(\mathrm{g} / \mathrm{cm}^{2}\right)$ & $1.151 \pm 0.041$ & $1.144 \pm 0.040$ \\
Total body fat $(\%)$ & $43 \pm 3.1$ & $39 \pm 3.5$ \\
Total body fat $(\mathrm{kg})$ & $34 \pm 4.8$ & $32 \pm 5.1$ \\
\hline
\end{tabular}

Data are the means \pm S.E.M. $(n=10)$. Total body water and lean body mass are shown in Fig. 2. BMC, bone mineral content; BMD, bone mineral density. by more than 2 -fold at 1 month and remained similarly elevated at 3 months of intervention $(P=0.014$ overall effect; Fig. 4. For comparison, we also give previously unanalyzed overnight pulsatile GH secretion rates in men administered $1 \mathrm{mg}$ GHRH twice daily (15). By two-way ANCOVA, stimulated GH secretion did not differ in women and men, but IGF-I rose less in women $(P<0.05)$. GH pulse number, secretory-burst
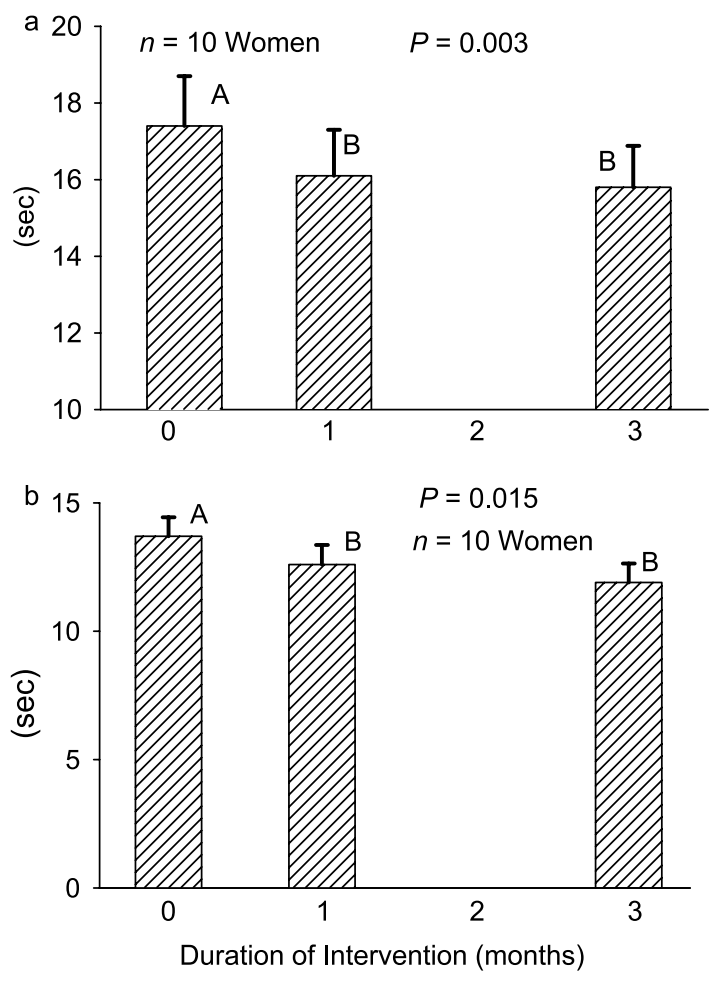

Figure 3 Time required to ascend two flights of stairs (a) or walk $30 \mathrm{~m}$ (b) assessed at baseline (time zero) and after 1 and 3 months of GHRH administration in ten postmenopausal individuals. The data format is that given in Fig. 1. 
Table 4 Cardiorespiratory responses to exercise.

\begin{tabular}{lcc}
\hline Measure & Baseline & 3 months \\
\hline Power & & \\
At LT (W) & $27 \pm 5$ & $31 \pm 6$ \\
Peak (W) & $106 \pm 14$ & $103 \pm 11$ \\
Oxygen consumption & & \\
At LT (ml/kg per min) & $8.2 \pm 1.0$ & $10.5 \pm 1.0$ \\
Peak (ml/kg per min) & $19 \pm 2.6$ & $22 \pm 2.6$ \\
BP at peak & & \\
Systolic (mmHg) & $205 \pm 9.8$ & $212 \pm 15$ \\
Diastolic (mmHg) & $83 \pm 4.1$ & $81 \pm 5.3$ \\
Heart rate (maximum) (b.p.m.) & $163 \pm 10$ & $164 \pm 8$ \\
Relative perceived exertion at LT & $8.0 \pm 0.88$ & $8.7 \pm 1.1$ \\
\hline
\end{tabular}

Data are the means \pm S.E.M. $(n=10)$. Values at baseline and at 3 months do not differ significantly. LT, lactate threshold.

Table 5 Measures of quadriceps and biceps femoris strength.

\begin{tabular}{lll}
\hline Measure & Baseline & 3 months \\
\hline $\begin{array}{l}\text { Average force } \\
\text { Extension }\end{array}$ & & \\
$\quad$ Concentric & $282 \pm 24$ & $278 \pm 33$ \\
$\quad$ Eccentric & $369 \pm 26$ & $362 \pm 31$ \\
Flexion & & \\
$\quad$ Concertric & $125 \pm 13$ & $131 \pm 14$ \\
Eccentric & $197 \pm 22$ & $182 \pm 15$ \\
Peak force & & \\
Extension & & \\
$\quad$ Concentric & & $391 \pm 41$ \\
$\quad$ Eccentric & $400 \pm 37$ & $504 \pm 40$ \\
Flexion & $510 \pm 33$ & $172 \pm 12$ \\
$\quad$ Concentric & & $255 \pm 19$ \\
Eccentric & $158 \pm 14$ & \\
\hline
\end{tabular}

Data do not differ at baseline and at 3 months. Values are the means \pm S.E.M. $(n=10)$.

Table 6 Duration of postured balance (s).

\begin{tabular}{|c|c|c|}
\hline Outcome & Baseline & 3 months \\
\hline Sharpened Romberg & $28 \pm 12$ & $34 \pm 9$ \\
\hline \multicolumn{3}{|l|}{ Dominant leg } \\
\hline Eyes closed & $40 \pm 5$ & $40 \pm 6$ \\
\hline Eyes open & $10 \pm 4$ & $18 \pm 6$ \\
\hline \multicolumn{3}{|l|}{ Non-dominant leg } \\
\hline Eyes closed & $16 \pm 5$ & $17 \pm 6$ \\
\hline Eyes open & $42 \pm 4$ & $43 \pm 6$ \\
\hline
\end{tabular}

Data are the means \pm S.E.M. $(n=10)$. Values do not differ at baseline and at 3 months.

duration and basal secretion rates were not affected by GHRH administration (not shown).

The ApEn statistic identifies feedback adaptations (regularity of patterned hormone release) with high sensitivity and specificity (see Methods section). Thus, ApEn was used to test the hypothesis that GHRH-stimulated pulsatile GH secretion remains orderly. Figure 5 shows that prolonged GHRH drive in the face of jointly

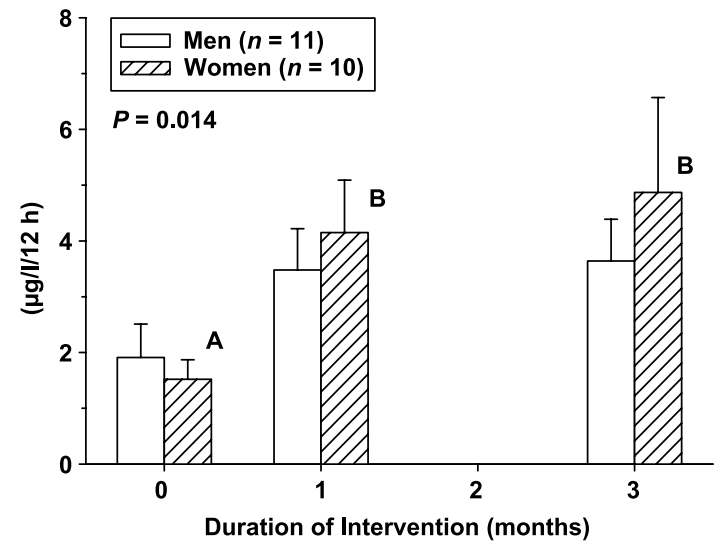

Figure 4 Pulsatile GH secretion rates ( $\mu \mathrm{g} / \mathrm{l}$ per $12 \mathrm{~h}$ ) determined in ten postmenopausal women (present study) and results analyzed for the first time from earlier GH profiles in 11 older men (15). Volunteers underwent blood sampling at 10-min intervals overnight before and after 1 months and 3 months of twice-daily s.c. administration of $1 \mathrm{mg} \mathrm{GHRH}$. The overall interventional $P$ value is given. There were no gender differences. See Fig. 1 for data format.

elevated GH and IGF-I concentrations markedly enhances orderliness of $\mathrm{GH}$ release patterns (overall $P<0.001$ ), as indicated by a fall in GH ApEn at both 1 and 3 months $(P<0.001$ in women and $P<0.01$ in men vs baseline). There was no gender effect, and values at 1 month and 3 months did not differ from each other.

Seven of ten volunteers experienced significant skin reactivity at the injection site, defined by any two or more a priori features of localized edema $(>2.0 \mathrm{~cm})$, soreness, erythema or pruritus persisting for $>24$ hours after GHRH injection. None of the volunteers reported signs or symptoms of systemic histamine release, defined as unexplained hypotension,

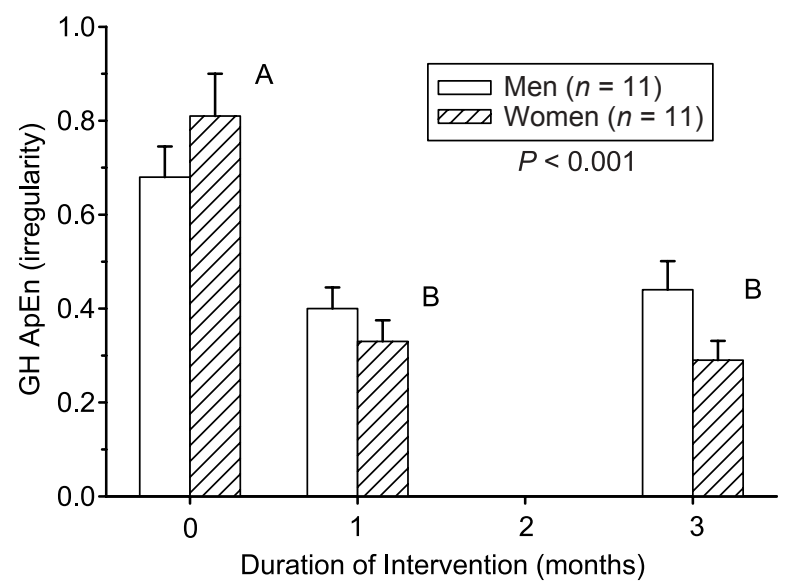

Figure 5 GHRH administration lowers approximate entropy (ApEn), a quantitative measure of irregularity (relative randomness) of GH release patterns. A lower ApEn indicates enhanced orderliness, which denotes stronger feedback inputs. In other respects, data are presented as described in the legend of Fig. 4. 
generalized urticaria, angioedema, vocal hoarseness or wheezing. Two subjects described weight gain $>2 \mathrm{~kg}$ and/or arthralgias, and one developed mild carpaltunnel syndrome. The average weight gain for the cohort was $0.04 \pm 1.3 \mathrm{~kg}$. None of the volunteers discontinued participation. There were no significant changes in general chemistry, blood glucose or insulin, or clinical cardiac function.

\section{Discussion}

The present investigation demonstrates that administration of a high dose of rhGHRH-1,44-amide (1 mg s.c. twice daily) for 3 months doubles 12-h mean GH concentrations and increases IGF-I concentrations by $71 \%$ in postmenopausal women. The GHRH intervention decreased abdominal visceral fat by $16 \%$, increased total body water by $14 \%$, and reduced the $30 \mathrm{~m}$ walk time by $14 \%$ and the stair-climb time by $9 \%$. Aerobic capacity, flexibility, balance, bone mineral density, lean body mass and muscle strength did not change significantly over the 3 months. Seventy per cent of the volunteers met two or more criteria for bothersome local skin reactions. None exhibited systemic histamine release. Taken together, these data extend earlier studies in men by establishing proof-of-principle that an adequate amount and schedule of GHRH administration can stimulate $\mathrm{GH}$ and IGF-I production for as long as 3 months, alter body composition and enhance certain performance measures in healthy postmenopausal individuals. Side effects include significant local skin reactivity to this dose and route of peptide administration.

Healthy older men given 1 or $4 \mathrm{mg}$ GHRH s.c. twice daily for 3 months responded with elevated $\mathrm{GH}$ and IGF-I concentrations and dose-dependent changes in body composition (15). Pilot studies in women revealed that the $4 \mathrm{mg}$ GHRH dose could not be tolerated due to marked skin reactivity triggered by histamine release. On the other hand, administration of smaller doses of GHRH-1,29) once daily for as long as 4 months stimulated GH release only briefly after each injection in elderly adults, and did not sustain IGF-I elevations or alter physical endpoints and performance outcomes $(10,13)$. The current intensive regimen of a high dose of GHRH administered twice daily significantly increased GH and IGF-I production and induced body-compositional and functional improvements in healthy older women. Whether the slightly longer half-life of GHRH-1,44 compared with that of GHRH-1,29 also contributed to these response differences is not known (1).

In the current investigation, GHRH administration in postmenopausal volunteers did not alter bone density or muscle mass over the 3-month intervention. The identical dose and schedule of GHRH supplementation in healthy older men augmented lean body mass, whereas a 4-fold higher GHRH dose was required to decrease abdominal visceral fat content (15). Post hoc comparisons of GHRH effects in men and women revealed comparable increases in pulsatile $\mathrm{GH}$ secretion and enhanced regularity of GH release (Figs 4 and 5), but lower IGF-I levels in women. Distinguishable tissue effects in women and men despite commensurately elevated $\mathrm{GH}$ concentrations would be consistent with sex differences in target-organ responsiveness, as inferred in hypopituitary adults treated with GH (38). Direct comparison between GH and GHRH supplementation would be of interest in this regard.

GHRH administration for 1 and 3 months enhanced the quantifiable orderliness of $\mathrm{GH}$ release patterns, as monitored by the approximate entropy statistic (33-35). Heightened GH regularity after GHRH exposure differs from the acute effects of this and other secretagogues, which reduce orderliness of $\mathrm{GH}$ release and thus mimic profiles observed in puberty (14, 39-41). Based upon biomathematical modeling, enhanced GH regularity following sustained GHRH stimulation would predict more effectual feedback restraint within the GH-IGF-I axis (35, 42, 43). Known feedback signals are elevated concentrations of GH and IGF-I, which putatively evoke central somatostatin outflow $(1,44)$. The latter would account for the present outcome, since somatostatin infusion also enforces more orderly GH secretion (45). A clinical distinction is that administration of GHRH (present data) but not GHRP-2 (14) for 1 month evokes more regular GH secretion. This contrast is consistent with the inferred capability of GHRP but not GHRH to attenuate somatostatinergic restraint (46).

Untoward local skin reactions were common after s.c. injection of $1 \mathrm{mg}$ GHRH twice daily in elderly women. Systemic release of histamine was not observed. Two participants developed arthralgia and/or weight gain $>2 \mathrm{~kg}$, and one reported carpaltunnel syndrome. Such adverse events are consistent with an increase in total body water associated with elevated GH concentrations, as also observed during GH administration $(16,17)$. Clinical cardiac function and fasting glucose concentrations did not change.

Interpretative qualifications include selection of successfully aging volunteers capable of completing an intensive 3-month protocol. In the case of performance measures, a small training effect cannot be excluded in a longitudinal design. Four women were receiving postmenopausal HRT, but their responses were not distinguishable by subanalyses from those of the other six volunteers. The present results in healthy, community-living, unmedicated individuals would not necessarily apply equally to individuals with significant age-related frailty or systemic illness. In addition, the outcomes obtained here in ten women will require confirmation in a larger cohort of volunteers with longitudinal parallel placebo exposure.

In conclusion, twice-daily s.c. administration of a high dose of rhGHRH for 3 months elevates $\mathrm{GH}$ and 
IGF-I concentrations in postmenopausal women, reduces abdominal visceral fat mass, increases total body water, improves certain measures of physical performance and elicits significant local skin reactions. Further investigations will be required to determine the impact of more prolonged delivery of GHRH on the GH-IGF-I axis, body composition and functional status in aging individuals.

\section{Acknowledgments}

The authors thank Kris Nunez for excellent assistance in manuscript preparation; the GCRC Core Assay Lab staff for performing the immunoassays; and the GCRC nursing staff for conducting the research protocol. Studies were supported in part by: MO1 RR00847 and RR00585 to the General Clinical Research Centers of the University of Virginia and Mayo Clinic and Foundation from the National Center for Research Resources (Rockville, MD, USA); and R01 AG 14799 (J D V) from the National Institutes of Health (Bethesda, MD, USA).

\section{References}

1 Giustina A \& Veldhuis JD. Pathophysiology of the neuroregulation of growth hormone secretion in experimental animals and the human. Endocrine Review 199819 717-797.

2 Corpas E, Harman SM \& Blackman MR. Human growth hormone and human aging. Endocrine Review 199314 20-39.

3 Blum WF, Shavrikova EP, Edwards DJ, Rosilio M, Hartman ML, Marin F, Valle D, van der Lely AJ, Attanasio AF, Strassburger CJ, Henrich G \& Herschbach P. Decreased quality of life in adult patients with growth hormone deficiency compared with general populations using the new, validated, self-weighted questionnaire, questions on life satisfaction hypopituitarism module. Journal of Clinical Endocrinology and Metabolism 200388 4158-4167.

4 Cuneo RC, Salomon F, Watts GF, Hesp R \& Sonksen PH. Growth hormone treatment improves serum lipids and lipoproteins in adults with growth hormone deficiency. Metabolism 1993 42 1519-1523.

5 Lentjes EG, Romijn F, Maassen RJ, de Graaf L, Gautier P \& Moolenaar AJ. Free cortisol in serum assayed by temperature-controlled ultrafiltration before fluorescence polarization immunoassay. Clinical Chemistry $1993392518-2521$.

6 Arvat E, Ceda G, Ramunni J, Lanfranco F, Aimaretti G, Gianotti L, Broglio F \& Ghigo E. The IGF-I response to very low rhGH doses is preserved in human ageing. Clinical Endocrinology (Oxford) 1998 $49757-763$.

7 Lissett CA \& Shalet SM. The insulin-like growth factor-I generation test: peripheral responsiveness to growth hormone is not decreased with ageing. Clinical Endocrinology (Oxford) 200358 238-245.

8 Arvat E, Ceda GP, Di Vito L, Ramunni J, Gianotti L \& Ghigo E. Agerelated variations in the neuroendocrine control, more than impaired receptor sensitivity, cause the reduction in the GH-releasing activity of GHRP's in human aging. Pituitary 19981 51-58.

9 Mueller EE, Cella SG, Parenti M, Deghenghi R, Locatelli V, De Gennaro Colonna V, Torsello A \& Cocchi D. Somatotropic dysregulation in old mammals. Hormone Research 199543 39-45.

10 Vittone J, Blackman MR, Busby-Whitehead J, Tsiao C, Stewart KJ, Tobin J, Stevens T, Bellantoni MF, Rogers MA, Baumann G, Roth J, Harman SM \& Spencer RG. Effects of single nightly injections of growth hormone-releasing hormone (GHRH 1-29) in healthy elderly men. Metabolism: Clinical and Experimental 199746 89-96.

11 Corpas E, Harman SM, Piñeyro MA, Roberson R \& Blackman MR. Growth hormone (GH)-releasing hormone-(1-29) twice daily reverses the decreased $\mathrm{GH}$ and insulin-like growth factorI levels in old men. Journal of Clinical Endocrinology Metabolism 199275 530-535.

12 Corpas E, Harman SM, Pineyro MA, Roberson R \& Blackman MR. Continuous subcutaneous infusions of growth hormone $(\mathrm{GH})$ releasing hormone 1-44 for 14 days increase GH and insulinlike growth factor-I levels in old men. Journal of Clinical Endocrinology and Metabolism 199376 134-138.

13 Khorram O, Laughlin GA \& Yen SSC. Endocrine and metabolic effects of long-term administration of $\left[\mathrm{Nl}^{27}\right]$ growth hormonereleasing hormone-(1-29)- $\mathrm{NH}_{2}$ in age-advanced men and women. Journal of Clinical Endocrinology and Metabolism 1997 $821472-1479$.

14 Bowers CY, Granda R, Mohan S, Kuipers J, Baylink D \& Veldhuis JD. Sustained elevation of pulsatile growth hormone (GH) secretion and insulin-like growth factor I (IGF-I), IGF-binding protein-3 (IGFBP-3), and IGFBP-5 concentrations during 30-day continuous subcutaneous infusion of GH-releasing peptide-2 in older men and women. Journal of Clinical Endocrinology and Metabolism $2004892290-2300$.

15 Veldhuis JD, Patrie JT, Frick K, Weltman JY \& Weltman A. Sustained GH and IGF-I responses to prolonged high-dose twicedaily GHRH stimulation in middle-aged and older men. Journal of Clinical Endocrinology and Metabolism 200489 6325-6330.

16 Munzer T, Harman SM, Hees P, Shapiro E, Christmas C, Bellantoni MF, Stevens TE, O'Connor KG, Pabst KM, St Clair C, Sorkin JD \& Blackman MR. Effects of GH and/or sex steroid administration on abdominal subcutaneous and visceral fat in healthy aged women and men. Journal of Clinical Endocrinology and Metabolism 200186 3604-3610.

17 Gotherstrom G, Svensson J, Koranyi J, Alpsten M, Bosaeus I, Bengtsson B \& Johannsson G. A prospective study of 5 years of GH replacement therapy in GH-deficient adults: sustained effects on body composition, bone mass, and metabolic indices. Journal of Clinical Endocrinology and Metabolism 200186 4657-4665.

18 Nashner LM \& Peters JF. Dynamic posturography in the diagnosis and management of dizziness and balance disorders. Neurologic Clinics 19908 331-349.

19 Roemmich JN, Clark PA, Weltman A \& Rogol AD. Alterations in growth and body composition during puberty: I Comparison among 2-, 3-, and 4-compartment models of body composition. Journal of Applied Physiology 199783 927-935.

20 Katch FI, Michael ED \& Horvath SM. Estimation of body volume by underwater weighing: description of a single method. Journal of Applied Physiology 196723 811-816.

21 Wilmore JH. A simplified method for determination of residual lung volumes. Journal of Applied Physiology 196927 96-100.

22 Weltman A, Despres JP, Clasey JL, Weltman JY, Wideman L, Kanaley J, Patrie J, Bergeron J, Thorner MO, Bouchard C \& Hartman ML. Impact of abdominal visceral fat, growth hormone, fitness, and insulin on lipids and lipoproteins in older adults. Metabolism 200352 73-80.

23 Clasey JL, Bouchard C, Wideman L, Kanaley JA, Teates CD, Thorner MO, Hartman ML \& Weltman A. The influence of anatomical boundaries, age, and sex on the assessment of abdominal visceral fat. Obesity Research 19975 395-401.

24 Iranmanesh A, Grisso B \& Veldhuis JD. Low basal and persistent pulsatile growth hormone secretion are revealed in normal and hyposomatotropic men studied with a new ultrasensitive chemiluminescence assay. Journal of Clinical Endocrinology Metabolism $199478526-535$.

25 Veldhuis JD, Liem AY, South S, Weltman A, Weltman J, Clemmons DA, Abbott R, Mulligan T, Johnson ML, Pincus SM, Straume M \& Iranmanesh A. Differential impact of age, sex-steroid hormones, and obesity on basal versus pulsatile growth hormone secretion in men as assessed in an ultrasensitive chemiluminescence assay. Journal of Clinical Endocrinology Metabolism $1995803209-3222$.

26 Shah N, Evans WS \& Veldhuis JD. Actions of estrogen on the pulsatile, nyctohemeral, and entropic modes of growth hormone 
secretion. American Journal of Physiology $1999 \mathbf{2 7 6}$ R1351-R1358.

27 Veldhuis JD, Carlson ML \& Johnson ML. The pituitary gland secretes in bursts: appraising the nature of glandular secretory impulses by simultaneous multiple-parameter deconvolution of plasma hormone concentrations. PNAS 198784 7686-7690.

28 Veldhuis JD, Evans WS \& Johnson ML. Complicating effects of highly correlated model variables on nonlinear least-squares estimates of unique parameter values and their statistical confidence intervals: estimating basal secretion and neurohormone half-life by deconvolution analysis. Methods of Neuroscience 199528 130-138.

29 Faria ACS, Veldhuis JD, Thorner MO \& Vance ML. Half-time of endogenous growth hormone $(\mathrm{GH})$ disappearance in normal man after stimulation of GH secretion by GH-releasing hormone and suppression with somatostatin. Journal of Clinical Endocrinology and Metabolism 198968 535-541.

30 Veldhuis JD \& Johnson ML. Cluster analysis: a simple, versatile and robust algorithm for endocrine pulse detection. American Journal of Physiology 1986250 E486-E493.

31 Keenan DM, Licinio J \& Veldhuis JD. A feedback-controlled ensemble model of the stress-responsive hypothalamo-pituitary-adrenal axis. PNAS 200198 4028-4033.

32 Keenan DM, Alexander SL, Irvine CHG, Clarke IJ, Canny BJ, Scott CJ, Tilbrook AJ, Turner AI \& Veldhuis JD. Reconstruction of in vivo time-evolving neuroendocrine dose-response properties unveils admixed deterministic and stochastic elements in interglandular signaling. PNAS $20041016740-6745$.

33 Pincus SM. Irregularity and asynchrony in biologic network signals. Methods in Enzymology 2000321 149-182.

34 Veldhuis JD, Johnson ML, Veldhuis OL, Straume M \& Pincus S. Impact of pulsatility on the ensemble orderliness (approximate entropy) of neurohormone secretion. American Journal of Physiology 2001281 R1975-R1985.

35 Veldhuis JD, Straume M, Iranmanesh A, Mulligan T, Jaffe CA, Barkan A, Johnson ML \& Pincus SM. Secretory process regularity monitors neuroendocrine feedback and feedforward signaling strength in humans. American Journal of Physiology $2001 \mathbf{2 8 0}$ R721-R729.

36 Zar JH. Biostatistical Analysis, 3rd edn, Upper Saddle River, NJ, USA: Prentice Hall, 1996.

37 Myers RH. Classical and Modern Regression with Applications, 2nd edn, Belmont, CA, USA: Duxbury Press, 1990.

38 Burman P, Johansson AG, Siegbahn A, Vessby B \& Karlsson FA. Growth hormone (GH)-deficient men are more responsive to $\mathrm{GH}$ replacement therapy than women. Journal of Clinical Endocrinology Metabolism 199782 550-555.

39 Iranmanesh A, South S, Liem AY, Clemmons D, Thorner MO, Weltman A \& Veldhuis JD. Unequal impact of age, percentage body fat, and serum testosterone concentrations on the somatotrophic, IGF-I, and IGF-binding protein responses to a three-day intravenous growth hormone-releasing hormone pulsatile infusion in men. European Journal of Endocrinology 1998139 59-71.

40 Evans WS, Anderson SM, Hull LT, Azimi PP, Bowers CY \& Veldhuis JD. Continuous 24-hour intravenous infusion of recombinant human growth hormone (GH)-releasing hormone-(1,44)amide augments pulsatile, entropic, and daily rhythmic GH secretion in postmenopausal women equally in the estrogen-withdrawn and estrogen-supplemented states. Journal of Clinical Endocrinology and Metabolism 200186 700-712.

41 Veldhuis JD, Roemmich JN \& Rogol AD. Gender and sexual maturation-dependent contrasts in the neuroregulation of growth hormone secretion in prepubertal and late adolescent males and females - a general clinical research center-based study. Journal of Clinical Endocrinology and Metabolism 200085 2385-2394.

42 Farhy LS, Straume M, Johnson ML, Kovatchev B \& Veldhuis JD. Unequal autonegative feedback by $\mathrm{GH}$ models the sexual dimorphism in GH secretory dynamics. American Journal of Physiology 2002282 R $753-R 764$.

43 Farhy LS \& Veldhuis JD. Putative GH pulse renewal: periventricular somatostatinergic control of an arcuate-nuclear somatostatin and GH-releasing hormone oscillator. American Journal of Physiology 2004286 R1030-R1042.

44 Mueller EE, Locatelli V \& Cocchi D. Neuroendocrine control of growth hormone secretion. Physiological Reviews 199979 511-607.

45 Bray MJ, Vick TM, Shah N, Anderson SM, Rice LW, Iranmanesh A, Evans WS \& Veldhuis JD. Short-term estradiol replacement in postmenopausal women selectively mutes somatostatin's dosedependent inhibition of fasting growth hormone secretion. Journal of Clinical Endocrinology Metabolism 200186 3143-3149.

46 Fairhall KM, Mynett A \& Robinson IC. Central effects of growth hormone-releasing hexapeptide (GHRP-6) on growth hormone release are inhibited by central somatostatin action. Journal of Endocrinology 1995144 555-560.

Received 22 February 2005

Accepted 31 August 2005 